\section{Group Intercultural Competence: Adjusting and Validating Its Concept and Development Process}

\author{
Desenvolvimento de Competências Interculturais Grupais em Equipes \\ Multiculturais
}

\author{
Janete Schmidmeier ${ }^{1}{ }^{\circ}$ \\ Adriana Roseli Wunsch Takahashi ${ }^{1}$ \\ Janaina Maria Bueno ${ }^{2}$
}

\section{ABSTRACT}

Intercultural competence is a topic that has been increasingly focused on academic researches, mainly related to the context of multinational companies and multicultural teams. The literature on intercultural competence is broad, permeated with many concepts and models of its development, but the main focus is on individual (cognitive/behavioral approach). There are few studies on the group level whose approach emphasize the process. The objective of this study was to empirically test the concept of group intercultural competence (GIC) and analyze its development in multicultural teams, as indicated by Leung, Ang and Tan (2014). This research can be characterized as qualitative, of exploratory-descriptive type, with an interpretive approach that embraces sequential intramethod triangulation, with interpretative and content analysis. As the results, the process of GIC development was found to occur towards more mature levels of GIC and to be characterized by an upward spiral pyramidal process, where the lowest level evolves to higher levels of GIC through a cycle of inter-cultural learning. This development occurs over time and is permeated by conflict, reflection and change, covering the elements of GIC: interaction, efficacy, cultural differences, intercultural learning and communication, such as cause and consequence. Based on the theoretical and empirical contributions, it was possible to adjust and validate a proposed GIC concept, to adjust the relevant elements and dimensions for GIC analysis, and to understand how the GIC is developed through a procedural perspective where there is an intercultural learning cycle permeated by conflicts, reflections, interaction and changes.

Keywords: group intercultural competence; intercultural management; multicultural teams; multinational companies; intercultural learning.

JEL Code: M14, D83, C92.

\footnotetext{
' Universidade Federal do Paraná, Departamento de Ciências Sociais, Curitiba, PR, Brazil.

${ }^{2}$ Universidade Federal de Uberlândia, Faculdade de Gestão e Negócios, Uberlândia, MG, Brazil.
}

RESUMO

A competência intercultural é um tema que tem sido cada vez mais foco de estudos, principalmente relacionados ao contexto de empresas multinacionais e equipes multiculturais. A literatura sobre competência intercultural é ampla, permeada de muitos conceitos e modelos de desenvolvimento, porém o foco predominante é individual (abordagem cognitiva/comportamental). Poucos são os estudos sobre o desenvolvimento da CIG em nível grupal com abordagem que enfatize o processo. Com esta pesquisa objetivou-se testar empiricamente o conceito de competência intercultural grupal (CIG) e analisar o seu desenvolvimento em equipes multiculturais, conforme lacuna apontada por Leung, Ang e Tan (2014). Esta pesquisa é de natureza qualitativa, do tipo exploratório-descritivo, abordagem interpretativa com triangulação intramétodo sequencial e utilizadas análises interpretativas de dados e de conteúdo. Como resultado, identificou-se que o processo de desenvolvimento da CIG ocorre em direção a níveis mais maduros de CIG, caracterizado por um processo em espiral piramidal ascendente, onde o nível mais baixo evolui para níveis mais altos de CIG em um ciclo de aprendizagem intercultural. Esta evolução ocorre ao longo do tempo e é permeada pelo conflito, reflexão e mudança, abrangendo os elementos da CIG: interação, eficácia, diferenças culturais, aprendizagem intercultural e comunicação intercultural, como causa e consequência. Como contribuição teórica e empírica, foi possível ajustar e validar o conceito de CIG, identificar os elementos e dimensões para sua análise e compreender como a GIC é desenvolvida, em uma perspectiva processual, onde há um ciclo de aprendizagem intercultural permeado por conflitos, reflexões, interações e mudanças.

Palavras-chave: competência intercultural grupal; administração intercultural; equipes multiculturais; empresas multinacionais; aprendizagem intercultural.

Cite as: Schmidmeier, J., Takahashi, A. R. W., \& Bueno, J. M. (2020) Group intercultural competence: Adjusting and validating its concept and development process. Revista de Administração Contemporânea, 24(2), 151-166. https://doi.org/10.1590/1982-7849rac2020190021

Editor-in-chief: Wesley Mendes-Da-Silva

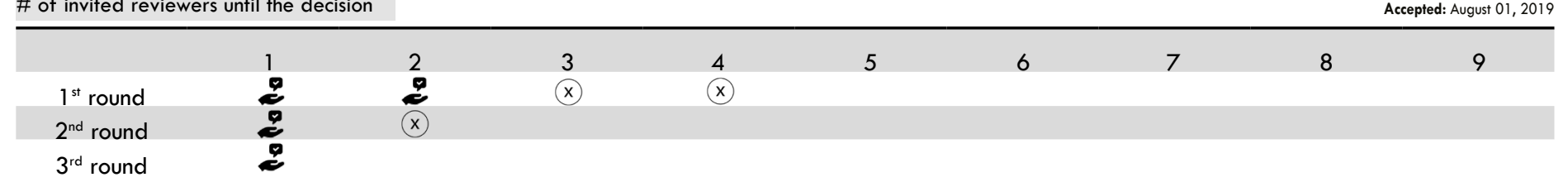




\section{INTRODUCTION}

Companies have increasingly felt the need to develop global strategies to obtain satisfactory results in a global environment, where intercultural coexistence plays an important position in organizational and social life (Adler \& Gundersen, 2008; Bueno \& Freitas, 2015). In the context of a globalized world, studies on Intercultural Competence (IC) have emerged in order to understand how it influences the performance of individuals, teams and organizations. There are many definitions for IC and diverse fields of knowledge that investigate it (Spitzberg \& Changnon, 2009; Bird, Mendenhall, Stevens, \& Oddou, 2010). One of the most widely accepted definitions of IC in the literature is that it is the ability to interact effectively with culturally different people (Wang, Taiwen, Freeman, Fan, \& Zhu, 2014). It is understood and studied from an individual perspective with focus on the cognitive and behavioral dimensions (Deardorff, 2015; Hammer, 2015). By analyzing the various studies published on IC, one can observe that most explore the theme in an individual dimension, considering the cultural dimension the mere context of competence use by the individual or manager. Thus, there is a gap in international IC literature when it comes to group and organizational IC.

Considering that the multicultural environment demands that multicultural teams develop specific skills to ensure high performance, and that a growing number of multicultural teams work in companies with international activities, this study discusses IC on a group level within multinational companies MNCs) and questions how these skills are developed and their implications on the performance of multicultural teams. When it comes to encounters among culturally diverse subjects, a notorious characteristic of MNCs (Adler \& Gundersen, 2008), it is believed that working under such conditions urges the development of specific competencies. The communication process, cultural diversity management, and intercultural differences and conflicts have been the most common challenges for multicultural teams (Matveev \& Nelson, 2004). Likewise, assuring group cohesion can be challenging, as the dynamics and consequences of diversity become more pronounced among groups (Lauring \& Selmer, 2010).

Few studies have shown concern for group IC (Leung, Ang \& Tan, 2014), and among these (Moynihan, Peterson \& Earley, 2006; Groves \& Feyerherm, 2011; Adair, Hideg \& Spence, 2013; Chen \& Lin, 2013), the focus is on processes underlying group IC, such as the relationship to intercultural efficacy and its development conditions and one of the latest studies in this level of analysis (Schmidmeier \& Takahashi, 2018) proposes the concept of Group Intercultural Competence - GIC, based on the literature. Based on this concept, this paper aims to empirically test the concept of GIC and analyze how such competence is developed among multicultural teams within MNCs. The context of MNCs was chosen because it presents the ideal locus for the development of phenomena addressing the group dimension and the multicultural context. According to Deardorff (2009, 2015) IC studies are negligent in that they focus on the individual, and overlook the aspects of the relationship from a social interaction perspective, challenging researchers to do so. The procedural dimension is adopted, as it emphasizes the course, allowing a complex, dynamic, and historically contextualized conceptualization (Martin, 2015).

Therefore, this study intends to contribute to the debate around the collective intercultural competences as asked by Leung, Ang and Tan (2014), Deardorff (2015) and Hammer (2015) on definition of a GIC concept and its dimensions, its developmental processes within multicultural teams, as well as its facilitating and inhibiting factors.

\section{LITERATURE REVIEW}

There have been several definitions for IC formulated by specialists on interculturality, and validated by managers of university programs, as suggested by Deardorff (2004), and presented in Figure 1.

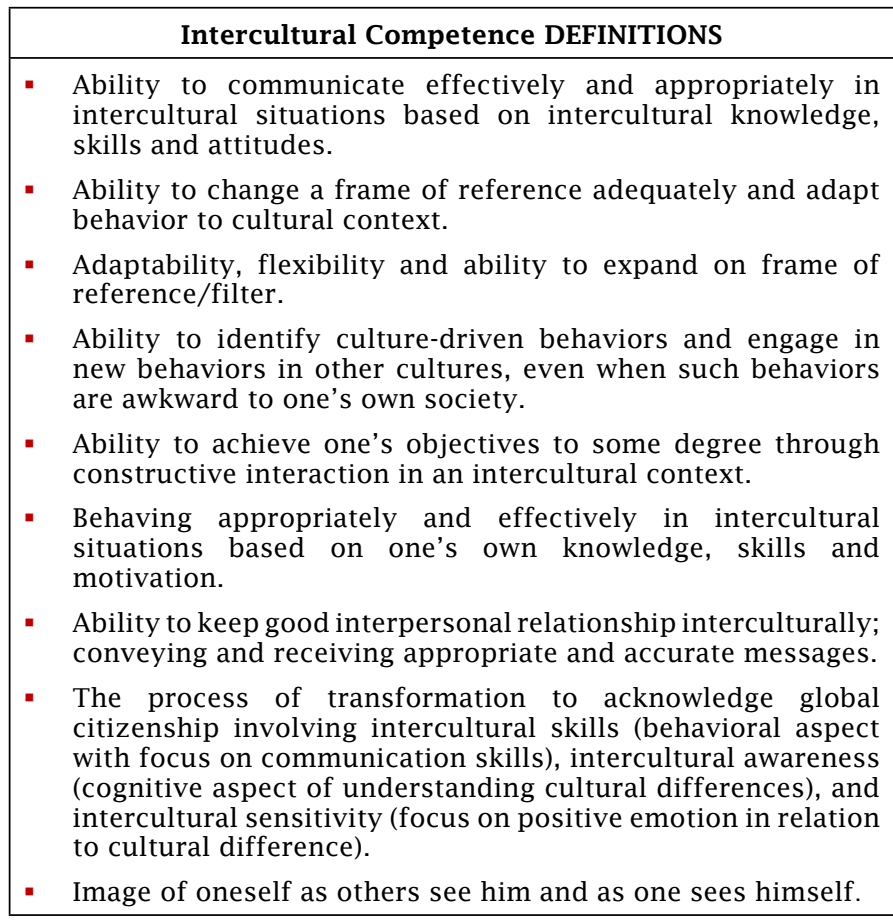

Figure 1. Definitions of Intercultural Competence.

Source: Adapted from Deardorff, D. K. (2004). The identification and assessment of intercultural competence as a student outcome of internationalization at institutions of higher education in the United States (Doctoral dissertation, p. 316). North Carolina State University, Raleigh, North Carolina, USA. 
As can be observed, the elements that make up IC stand out in the definitions, as if demonstrating how it is composed were the way to conceptualize it. Having that in mind, and hoping to capture contributions from the literature to advance the concept of GIC, a first step was to analyze the publications on the topic, select the various definitions, and then extract and list the elements present in them. A second step involved reflecting on which of these elements could migrate from an individual to a collective logic and create a new list, whose elements can be thought of organizationally, such as communication. For each definition and element, an analysis pointed to whether the focus was cognitive, behavioral and/or cultural, and whether it was individual or collective (implicit or explicit). Whenever the definitions featured the group as relevant, even though not explicitly, they were especially considered. The Table 1 demonstrates the elements extracted from the definitions for a collective analysis, the authors who exploit them, and the dimensions that make up each element. The IC definition hereby presented represents a synthesis of how authors who use this element consider it.

Table 1. Elements, Definitions and Dimensions for Group Intercultural Competence.

\section{Elements by Authors}

Deardorff (2004); Jokikokko (2005). Dinges and Baldwin (1996); Gertsen (1990); Bennett (1986).
Interaction management (Koester \& Olebe, 2003);

Team consolidation and engagement (Mendenhall \& Osland, 2002; Friedman \& Antal, 2005; Bird et al., 2010);

Cohesion among team members (Rathje, 2007);

Result orientation (Mendenhall \& Osland, 2002; Bird et al., 2010);

Strong, clear and detailed planning (Mendenhall \& Osland, 2002; Moran, Youngdahl \& Moran, 2009; Bird et al., 2010);

Understanding of the organization's strategic goals and team goals (Moran et al., 2009);

Clarity in describing roles (Moran et al., 2009).

Promotion of intercultural learning (Deardorff, 2004; Lasonen, 2005);

Ethnorelative vision (Deardorff, 2004);

Relationship building (Mendenhall \& Osland, 2002; Bird et al., 2010);

Diversity management (Panggabean, Murniati \& Tjitra, 2013);

Appreciation of group members' values, beliefs and behavior (Moran et al., 2009; Byram, 1997);

Appreciation of personal attributes (Fitch, 2012);

Non-judgmental standpoint (Byram, Nichols, \& Stevens 2001);

Mediated culture (Kim, 1988; Barmeyer \& Davoine, 2015);

Successful interactions (Hammer, Bennett \& Wiseman, 2003; Kupka, 2008);

Ability to manage complex situations (Lasonen, 2005);

Managing uncertainty (Bird et al., 2010).

Global Mindset (Bücker \& Poutsma, 2010);
Intellectual, cultural resources management (Moran et al., 2009);

Engagement of team members (Friedman \& Antal, 2005).

\section{Cultural differences}

Friedman and Antal (2005).

\section{Communication \\ Byram (1997); \\ Fitch (2012).}

Clear and frank communication (Moran et al., 2009);

Constant feedback (Moran et al., 2009);

Sociolinguistic ability (Deardorff, 2004);

Accuracy in conveying and receiving messages (Deardorff, 2004);

Ability to communicate interculturally (Byram, 1997; Mendenhall \& Osland, 2002; Bird et al., 2010; Lough, 2011; Fitch, 2012);

\section{Learning}

Fischer et al. (2009).

Ongoing intercultural learning (Mendenhall \& Osland, 2002; Bird et al., 2010);

Openness to intercultural learning (Deardorff, 2004);

Knowledge sharing orientation (Koester \& Olebe, 2003).

Flexibility (Deardorff, 2004);

Adaptability (Deardorff, 2004);

Mediated culture

Earley and Ang (2003); Mediated culture (Kim, 1988; Barmeyer \& Davoine, 2015);

Deardorff (2004); Barmeyer Ethnorelative vision - accepting the existence and importance of cultural differences within the and Davoine (2015). group (Deardorff, 2004);

Openness to intercultural learning (Deardorff, 2004).

Note. Source: data from literature review. 
A third stage for the elaboration of the GIC concept based on the elements listed for the group level was to analyze the results obtained with regard to definitions, elements and dimensions and develop a conceptual proposal for GIC based on the literature (Lane, DiStefano \& Maznevski, 2000; Gertsen, 1990; Dinges \& Baldwin, 1996; Byram, 1997; Bennet, 1986; Mendenhall \& Osland, 2002; Earley \& Ang (2003); Deardorff, 2004; Friedman \& Antal, 2005; Jokikokko, 2005; Moran et al., 2009; Bird et al, 2010; Lough, 2011; Fitch, 2012; Barmeyer \& Davoine, 2015): "GIC is the group's ability to achieve its objectives effectively through social interaction, efficient communication and negotiation of cultural differences, that result from a group learning process in a multicultural context" (Schmidmeier \& Takahashi, 2018, p. 147).

Having outlined the first version of the concept, what followed was the search for models of IC in the literature that would explain the development of the competence. It is noteworthy that, as a process, the competence may be at different levels of development in a given point in time and vary all along, as it is presumed as dynamic rather than static. The next section describes the models found and the elements they have covered.

\section{Intercultural competence development models}

Researchers have currently been directing their efforts to develop IC evaluation models on three levels of analysis: individual, group and organizational IC (Spitzberg \& Changnon, 2009; Leung et al., 2014). These authors have organized the existing models into 5 types: (a) composition models, (b) coorientation models, (c) development models, (d) adaptational models and (e) causal process models. These categories emerged from the search for similarities among the models (Spitzberg \& Changnon, 2009), aiming to draw their distinctions. In general, the models prioritize individual IC development, but nonetheless bring relevant contributions in two aspects: they sometimes transpose the logic to the group and touch on points that are present in the group. Such points were considered in the search for a model that would serve as reference for the analysis of GIC development and are summarized in the Table 2.

Table 2. Contributions from IC Development Models to GIC.

\begin{tabular}{|c|c|}
\hline Models & Contributions to the Analysis of GIC Development \\
\hline Composition Models & $\begin{array}{l}\text { - } \quad \text { Emphasize the compositional elements of IC; } \\
\text { - Suitable for individual IC studies. }\end{array}$ \\
\hline Coorientation Models & $\begin{array}{l}\text { - Emphasize the IC elements: communication and context, mediated culture, intercultural interaction; } \\
\text { - Emphasize the individual's intercultural knowledge. }\end{array}$ \\
\hline Development Models & $\begin{array}{l}\text { - Dynamic view of competence; } \\
\text { - Feature developmental stages with indicators for each stage; } \\
\text { - Highlight integration as a reference to groups with high degree of IC development; } \\
\text { - Emphasize group members' experiences with cultural differences; } \\
\text { - Recognize an inherent learning process underlying the development of IC, in spite of the adapta- } \\
\text { tional focus. }\end{array}$ \\
\hline Adaptational Models & $\begin{array}{l}\text { - Show possible styles of acculturation that are related to the stages of IC development; } \\
\text { - Integration reveals that multicultural groups may operate in a multi-collective system, and can be } \\
\text { associated with a group with high degree of IC development; } \\
\text { - Welcoming relationships are evidence of IC development. }\end{array}$ \\
\hline $\begin{array}{l}\text { Models of Causal Pro- } \\
\text { cesses }\end{array}$ & $\begin{array}{l}\text { - Recognize different levels of IC; } \\
\text { - Appreciate the interaction between different cultures, and knowledge. Recognize that there is an } \\
\text { intercultural learning; } \\
\text { - } \quad \text { Consider the influence of intercultural experience and communication; } \\
\text { - Highlight the need for managing changes to IC development; } \\
\text { - Present indicators for IC outcome that can be used to assess the extent of the group development. }\end{array}$ \\
\hline
\end{tabular}

Note. Source: Based on literature review, mainly Spitzberg, B. H., \& Changnon, G. (2009). Conceptualizing intercultural competence. In D. K. Deardorff (Ed.), The Sage handbook of intercultural competence (pp. 2-52). Thousand Oaks: SAGE Publications; also Rathje, S. (2007). Intercultural competence: The status and future of a controversial concept. Language and Intercultural Communication, 7(4), 254-266. https://doi.org/10.2167/laic285.0; and Panggabean, H., Murniati, J., \& Tjitra, H. (2013). Profiling intercultural competence of Indonesians in Asian workgroups. International Journal of Intercultural Relations, 37(1), 86-98.

https://doi.org/10.1016/j.ijintrel.2012.04.002 
Composition models seem to better address studies on the individual level, and, for this reason, they were not considered in this paper. Coorientation models prioritize communication and language skills, and were not adopted because they are more suitable for this approach focus; it is worth pointing out that these models reinforce the IC elements also identified for the analysis of the GIC.

On the other hand, the development models offered a more effective contribution to the analysis of GIC development. They adopt a dynamic view of competence, pose stages of development with indicators for each stage, highlight integration as a reference to groups with high degree of IC development, emphasize group members' experiences with cultural differences, recognize the underlying learning process along the IC development, despite of its adaptational focus (adjustments) as shown by Spitzberg and Changnon (2009). Therefore, the analysis took these issues into account.

Adaptational models contribute because they show possible styles of acculturation and consider integration a phase during which multicultural groups can operate in a multi-collective system. From a different angle, welcoming relationships are evidence of how each group interacts and develops GIC. Finally, causal process models also bring contributions to the investigation of GIC, despite their being characterized by causal relationships. The models show there are different levels of IC, value the interaction between different cultures and knowledge, recognize there is an intercultural learning, consider the influence of cross-cultural and communication experiences, highlight the need to manage changes, and show indicators for IC results that can be used to assess the group's degree of development (Spitzberg \& Changnon, 2009).

An in-depth analysis of these models generated a list of key terms for the development of GIC: time, elements and dimensions, development, dynamic and variable, recursion, knowledge, experiences, internships, levels, integration, welcoming and acculturation. On the basis of those keywords, it was assumed that the development of GIC is a process that occurs over time, since it is dynamic and variable, by means of the knowledge and experience of the group members concerning interaction, efficacy, intercultural relationship (cultural differences and mediated culture) and communication - the result of a learning process. As a process, it occurs in stages involving cognition, behavior and culture, interpersonal and intra-personal, and express levels where a mature stage of development implies high integration among group members and welcoming of new members (Bennett, 1986; Berry, Kim, Power, Young \& Bujaki, 1998; King \& Baxter-Magolda, 2005).
In order to analyze the development of CI in groups, we chose multicultural teams (predominantly present in MNCs) as the research locus. We used the Intercultural Sensitivity Development Model developed by Hammer, Bennett and Wiseman (2003) to assess the level of GIC development. The instrument measures the level of competence through a development process based on the ability to perceive cultural differences and similarities and to modify one's behavior in a cultural context (Hammer, 2011). The more mature stages of IC, according to the authors, are adaptation and integration. In the adaptation stage, individuals develop the ability to embrace another person's perspective or change one's frame of reference before other cultures. Transposing the argument to the group level, we can affirm that at this stage of development, the group has the capacity to adapt through openness, flexibility and articulation of cultural differences. At the integration stage, the final level of intercultural maturity, the adaptation of individuals in multicultural settings raises a question of one's own identity, making him feel part of the other's culture. Directing the point to the group level, we can say that in their efforts to adapt to cultural specificities of their members, groups generate change in their frame of reference, integrating cultural specificities in an environment of transparency and harmonious interaction. The dimension of integration is relevant here, as it denotes the highest level of IC development (Bennet, 1986; Bennet, 1993; Hammer, 2011), that is, a team with high degree of GIC development who has developed strong integration.

\section{RESEARCH METHODS}

This qualitative research adopted an exploratory-descriptive method. It is exploratory in that studies on the processes of group IC development and on the tendency of multicultural group forming in multinational companies is fairly recent (Leung et al., 2014) and lacks empirical support, and descriptive because it aimed to describe the characteristics (elements and dimensions) of a group competence. By seeking an in-depth reading of reality based on the assessment of those interviewed, it is predominantly interpretive. The method adopted is case study, in which the phenomenon of GIC is the case (Merriam, 1998), the level of analysis is organizational and the observation units are individuals working in multicultural teams.

On the basis of the literature gaps identified and the general objective of examining how GIC develops in multicultural teams within MNCs, the study design involved two phases of data collection 
and analysis. The first phase aimed to verify whether the proposed concept of GIC conformed to the reality of those who work within the context of intercultural groups. To that end, we conducted a survey with multinational professionals about the concept and the elements of group intercultural competence. The data collection was conducted via a closed and open-ended questions form, that was developed based on the literature and divided into 4 blocks: (a) general information; (b) elements of the GIC; (c) dimensions of the GIC; and (d) additional considerations. This form was personally administered to 20 individuals working in multicultural teams. Among the 20 participants, 16 were Brazilians working in MNCs (11 working abroad and 5 in Brazil) and 4 were foreigners ( 1 working in Brazil and 3 abroad). Concerning the length of time working in the team, it varied between 3 months and 10 years, with two respondents having been in the same team for more than eight years and 18 of them less than four years. The analysis of the closed-ended questions was done through simple descriptive statistics and the open-ended ones by content analysis (Flores, 1994).

The second stage commenced upon the reformulation of the concept which followed the analysis of the first stage and aimed to explore how GIC develops in the context of a multicultural team within a MNC. In order to analyse the process in greater depth, only one team was selected, so as to obtain more interaction. The choice of MNC for the second step, the case study, was marked by 4 selection criteria, namely: (a) represent the phenomenon under study; (b) be composed of members from 3 or more different cultures who often interrelate; (c) be a mature MNC with minimum 3-year-experience with intercultural coexistence within the team; and (d) willingness to participate in the study. The data were collected through personal interviews and focus-group. The in-depth individual interviews were conducted with semi-structured scripts with all 4 team members and the Human Resources Manager. The team works in the area of digital marketing and attend 10 countries in Latin America, being composed of 4 members: 1 Argentine, 2 Costa Ricans and 1 Brazilian. They interact with internal suppliers from several countries in Europe and the United States, working together for more than 3 years, except one who works in the team for 3 months. The interviews had 1 hour long an average, all of which were recorded and transcribed, generating a total of 98 pages.

Due to the displacement of some team members and the difficulty meeting them all within the same physical context, a focus group was adapted to be operated digitally by means of synchronous groups, that is, real time discussion (Flick, 2009). In so doing, we used the software available at the MNC for internal meetings and the focus group took 50 minutos. The questions for individual interviews and focus group scripts were grouped in blocks on: (a) understanding of the GIC development process based on the elements and (b) dimensions of the CI at the group level, mainly interaction, communication and mediated culture and (c) confirmation of the factors that have facilitated and hindered the GIC development process. The data were analyzed by means of the content analysis technique (Flores, 1994).

Although, triangulation of sources of evidence was performed to increase the quality of the research (Denzin, Lincoln \& Netz, 2007) in the second phase of the research. The transcript data from the individual interviews were analyzed and compared with the focus group data in each block of questions to reinforce the conclusions about the phenomenon in order to obtain a clear link between the evidences found in the empirical research (Gibbert, Ruigrok \& Wicki, 2008).

\section{FINDINGS AND DISCUSSION}

\section{Phase I - the concept of GIC}

The objective of this phase was to check the conformity of the proposed GIC concept and the 6 elements identified as relevant to the group dimension - interaction, efficacy, cultural differences, communication, learning and mediated culture - with their respective dimensions. The descriptive analysis of closed-ended questions pointed out that all six elements are relevant in the group context, since all were evaluated as relevant for more than $85 \%$ of the respondents. Upon this finding, an analysis of the degree of importance of the dimensions involved in GIC elements was carried out.

With respect to the Interaction, it was considered applicable, with emphasis on the dimensions Results Orientation and Understanding of the Team Goals, followed by Strong, Clear and Detailed Planning, also by Team Consolidation; Engagement; Cohesion Among Team Members; Understanding of the Strategic Objectives of the Organization; and Clarity in Describing Roles. Respect and tolerance were highlighted as factors that impact both the effective interaction of the group and the understanding of cultural differences. The Efficacy was considered relevant and the dimensions as a whole were regarded as slightly less important than the element 
of interaction. The dimensions that stood out were Non-judgemental Standpoint; Relationship Building; and Ability to Manage Complex Situations; followed by Appreciation of Personal Attributes; Successful Interactions; and then Appreciation for Group Members' Values, Beliefs and Behaviors; and Uncertainty Management. On the other hand, the dimensions Management of Cultural Diversity; Ethnorelative Vision; and Mediated Culture were below the $70 \%$ cut-off point defined for this research and were not considered valid.

The Cultural Differences was appointed as relevant and its dimension Engagement of Team Members was considered either important or very important by $100 \%$ of the respondents, followed by the dimension Intellectual and Cultural Resources Management; and Global Mindset. All IC dimensions pointed out by the literature and endorsed at this stage of the study were confirmed as important in articulating cultural differences within the MNC. Communication was considered applicable and had Clear and Frank Communication; and Accuracy in Conveying and Receiving Messages regarded as the most relevant dimensions. As for Constant Feedback, it was considered important or very important by $85 \%$ of the respondents, followed by Intercultural Communication Skills; and Verbal and Non-verbal Skills by $70 \%$. The dimension Social and Linguistic Skills did not reach $70 \%$ and therefore was not considered valid for the next phase, which can be explained by its similarity to the dimensions Intercultural Communication Skills; and Verbal and Non-verbal Skills.

The Learning was considered relevant and two dimensions stuck out, the Knowledge Sharing Orientation; and Openness to Intercultural Learning. The Ongoing Intercultural Learning dimension was not disclosed as important or very important to respondents. The Mediated Culture turned out to be applicable and three dimensions stood out for their level of importance, namely Flexibility; Adaptability; and Openness to intercultural learning.

The data analysis of the first phase of the study confirmed the relevance of the elements selected for group IC and considered by the proposed concept, but did not confirm all the dimensions for each element. With regard to the element of Interaction, what called attention was the importance of clarity in describing team goals and member roles, as well as the existence of a strong detailed planning, and group cohesion, sustained by the team consolidation and team engagement dimensions, which demanded further examination in the second phase of the study. As for the dimensions of respect and tolerance, which were made prominent, the literature reinforces that acquiring cultural understanding and respect for cultural differences is fundamental for diversity management (Dalib, Harun \& Yusoff, 2014). According to the authors, the importance of social relationships outside the workplace is relevant for effective group interaction (Gudykunst, Hammer \& Wiseman, 1977; Gertsen, 1990; Gertsen \& Soderberg, 2010).

The dimensions of Efficacy that had no relevance above $70 \%$ may not have been fully understood, as the terms Cultural Diversity Management; Ethnorelative Vision; and Mediated Culture involve more technical terms. Thus, we decided to carry out an exploration of these dimensions in the second phase. Concerning the Cultural Differences element, the dimensions that were fully accepted by the interviewees express the importance of interaction with people from other cultures, and confirm that the current theories on MNCs tend to focus on the difficulties and barriers faced by these teams and the need to face them (Bueno \& Freitas, 2015). Members' reports show that cultural differences within the team are no longer treated as an obstacle, but rather as a strength, and it is not an unusual feature, as it seems to have been internalized as something normal within organizations.

The analysis of the Communication element demonstrated that members of multicultural teams need clarity, accuracy, and communication skills to ensure effective communication. One of the Learning dimensions, Ongoing Intercultural Learning, was not regarded as important or very important. However, due to the degree of relevance shown by Mendenhall and Osland (2002) and Bird, Mendenhall, Stevens and Oddou (2010), who assert the dimension as fundamental in generating innovative and creative ideas in multicultural contexts, this dimension was maintained in the second stage, in order to confirm these results. Once again the dimensions Ethnorelative Vision; and Mediated Culture did not fit the parameters established by this study. As these two dimensions are emphasized in the literature as relevant and contain complex technical terms that may be difficult to understand, they were kept for analysis in the next phase. The mediated culture element had all its dimensions accepted and maintained.

Based on the analyses carried out in this first phase of the field approximation, some definitions were formulated: (a) all 6 elements of the IC literature - interaction, efficacy, cultural differences, communication, learning and mediated culture are relevant for the group analysis; and (b) the IC dimensions pointed out as not relevant (described above), but stressed in the literature as essential, were included in the design of the interview script for phase 2 , in order to further investigate their relevance. 
Finally, based on the analysis of frequency and the open-ended questions, the proposed concept was revised and underwent change, with the inclusion of the term Intercultural to specify the type of communication that takes place in GIC, and the inclusion of the term Articulation, to stress the importance of the interaction. The final wording of the concept was: group intercultural competence is the ability of the group to achieve its objectives effectively through social interaction, intercultural communication and efficient articulation of cultural differences, resulting from a process of group learning within a multicultural context. Based on the revised concept, we moved on to the second phase of the study, which aimed to explore how GIC develops in the context of a multicultural team within a MNC.

\section{Phase II: GIC development process}

Alpha is a MNC which boasts over 80 thousand employees worldwide, and operates in the pharmaceutical industry. The multicultural team under study was composed of 4 members - an Argentine, two Costa Ricans and a Brazilian - who worked together for over three years, except for interviewee 2 who had only joined the team three months earlier. They handled the digital marketing projects of 10 countries in Latin America. The team had autonomy in defining their goals and actions concerning the projects developed by their division in order to adapt them to the different demands of customer countries, which made them responsible for the entire operational strategy. The languages used for communication were Portuguese, Spanish and English, and fluency in all three languages was mandatory for all group members. Team interactions were face-to-face, and with customers and internal partners, they were exclusively digital, with formal mechanisms of social interaction.

As for the analysis of the elements and dimensions that make up the concept of GIC, this phase confirmed and also clarified some previous findings, which were important for the proposed concept and the analysis of the development process of GIC. In the case of Interaction, all its dimensions were granted present and relevant by all members of the MNC: "Yes [the team is highly integrated today], I think it's very integrated, very transparent, very communicative, everyone." (EC4). Some individual IC dimensions transposed to group analysis - results orientation, understanding of group goals, strong planning and understanding of strategic objectives were all regarded as inherent in results management, and not as separate issues. The other dimensions were confirmed.
The element of Efficacy emerged as a result of successful interactions. Therefore, these interactions were not perceived as one of the dimensions. Two dimensions were confirmed, and four others non-judgmental standpoint, relationship building, appreciation of personal attributes, and appreciation of values and behaviors - were seen as all being part of a single dimension of relationship.

The third element, Cultural Differences, had all of its dimensions confirmed by the team members. However, these dimensions suffered multiple changes, and engagement was the only that remained unchanged. Intellectual and cultural resource management, and global mindset were understood as belonging to the same sphere of global mindset. Ethnorelative vision (recognition of the existence and importance of cultural differences), flexibility and adaptability returned to the list, since we could confirm that they had not been understood in the form of the first phase. When interacting with the team and talking about the meaning of these dimensions, they proved relevant and appropriate to the respondents.

Communication was singled out as the cornerstone, the foundation of GIC, embedded in many narratives blended with other elements, whether it be as their cause or consequence. In this element too, all the dimensions were regarded as relevant by respondents, who claimed to present all of the dimensions, indicating high level of integration. Among them, 3 were unchanged and two - intercultural communication skills and verbal and non-verbal skills - were grouped and proposed under intercultural communication skills. The term intercultural was emphasized by all.

The fifth element of GIC, Learning, was pointed out as a condition to achieve team maturity and was presented as a process that occurs over time, and drives the team to higher levels of GIC. One dimension remained unchanged, one received the term Avoiding Stereotypes, and the other one had Trust added to it.

The last element investigated, Mediated Culture, was reported by the respondents as a result of successful interaction and communication, with an emphasis on flexibility and adaptability of the group. Therefore, intercultural negotiation took place in this team as a resource to ensure high level of GIC, whose dimensions are present in other elements.

At this stage of the study, the elements and their dimensions described earlier were analyzed, whether it be to confirm findings from phase I, or to clarify issues that remained unexplained. 
The dimension of Integration highlighted by the respondents, is relevant and denotes a higher level of IC development (Bennet, 1986; Bennet, 1993; Hammer, 2011), as the high level of integration contributed to the high level of GIC development. This high level of integration was a characteristic pointed out by the group as promoter of cohesion in the team, and could also be observed during the focus group. Whenever members were questioned about a certain topic, the entire group was encouraged to contribute with individual considerations. Some findings emerged from the interviews on these dimensions: (a) trust, openness and respect interfere directly in the cohesion among team members and their consolidation and engagement, through clarity in communication, leading the group to high performance; (b) the size of the team influences, but does not determine the existence of its cohesion; (c) results orientation and understanding of team goals are important in order to resolve possible conflicts arising from cultural communication problems and understanding the scope of projects; (d) knowledge of the team and organizational goals, as well as the planning associated with these goals, tend to reduce intercultural conflicts in carrying out tasks within the team, allowing different knowledge, skills and attitudes to contribute to group performance within the limits established by the organization and the MNC; (e) clarity in describing both team and individual member roles minimizes cultural differences, ensuring high group performance; (f) the existence of formal interaction mechanisms boosts interaction in that it encourages knowledge sharing and exchange of good practices; (g) exclusively digital contact is enough for interaction, but not efficient, so there is need for face-to-face contact among group members; and (h) length of time working together acts as a success factor in interaction, since it allows knowledge and adaptation to one's work style according to each culture.

It is worth mentioning that Efficacy was pointed out by the team as a result of their successful integration, in unison with the argument that a multicultural team's efficacy depends on the success of the interaction among its members (Hammer, Gudykunst \& Wiseman, 1978; Gudykunst \& Hammer, 1984, Hammer, Bennett, Wiseman, 2003). The findings on this were: (a) the construction of relationships is based on open-mindedness and empathy, which create opportunities to increase team flexibility and trust; (b) the ability to deal with complex situations generated by multiculturalism is relevant, since cultural diversity can generate a negative or positive impact for group efficacy depending on how it is managed by the team; and (c) appreciation of personal and cultural attributes that maximize the potential of the team to generate ideas and solve problems through successful interactions.

Having all dimensions under Cultural Differences confirmed, this item demonstrated that the ability to recognize and articulate these differences really impacts the formulation of effective actions to improve team results (Friedman \& Antal, 2005). Therefore, managing team cultural differences really seems to be critical in ensuring positive results (Chevrier, 2000; Kupka, 2008; Panggabean et al., 2013; Bueno \& Freitas, 2015), presenting itself, as with this team, as a resource for learning. The main findings on this item were: (a) cultural differences can act as facilitating or inhibiting factors within the MNC, depending on how they are treated by the group; (b) the challenges posed by cultural differences should be treated as resources for learning and for the improvement of group results; (c) team engagement is essential in managing cultural diversity and reducing conflicts generated by diversity; (d) cultural diversity generates optimization of the MNC's results when intellectual and cultural resources are well managed, a process defined as global mindset; (e) articulation of cultural diversity is influenced by group leadership, through clarity of goals, motivation, respect and openness to cultural differences.

Communication was singled out as the cornerstone, the foundation of GIC, embedded in many narratives blended with other elements, whether it be as their cause or consequence. The literature already points to this finding, since communication is seen as fundamental to the resolution of conflicts arising from cultural interaction among members of MNCs (Dusi, Messetti \& Steinbach, 2014; Soboleva \& Obdalova, 2014) and so that the team can operate effectively in any culture (Lloyd \& Härtel, 2010; Lough, 2011; Fitch, 2012; Bueno \& Freitas, 2015). In short, effective communication seems to reinforce the group's high level of GIC and impact other elements of GIC. The following observations should be noted: (a) clear and frank communication and accuracy in conveying messages guarantee the reduction of turbulence in intercultural communication; (b) the use of diversified communication channels must be adapted according to the cultural characteristics of the audience; (c) the use of cultural Interpreters reduces cultural distances between sender and receiver of the message; (d) the use of constant feedback guarantees the fluidity of communication; (e) length of time working together and group size influence intercultural communication.

Learning was confirmed as a process experienced by the team over time, and the dimensions validated converge with those emphasized in the literature and verified in the first 
phase of the study. The findings that emerged from the analysis were: (a) knowledge sharing orientation; and (b) openness to intercultural learning. The two dimensions were perceived as relevant by the group, who stressed the role of both in order to enhance improvement of interaction, efficacy, intercultural relationship and communication, with special attention to: (a) intercultural learning is driven by reciprocity in intercultural contact, the articulation of cultural differences and increasing intercultural sensitivity; (b) intercultural learning presumes management of changes that occur in the group; (c) knowledge sharing should be used as a tool for the alignment of experiences and expectations; (d) and openness to intercultural learning is supported by experience in multicultural environments.

Mediated culture was pointed out by respondents as occurring in connection with communication and integration, and not as an element in itself, an argument which is based on the theory that improvement of intercultural negotiation depends on social interaction, the group's flexibility and commitment, and on intercultural communication (Ferraro, 2001; Barmeyer \& Davoine, 2015). It was observed that all dimensions, although also present in other elements, were relevant for this team and explained their high level of GIC. Therefore, we found that: (a) intercultural negotiations are the result of successful interaction and communication; (b) clarity of group objectives and roles define the boundaries of what can be made more flexible and adapted in an intercultural negotiation; (c) trust among members of the MNC ensures openness and flexibility to negotiate cultural differences in a natural way; (d) intercultural learning is stimulated by disagreements within the group and is favored by openness, flexibility and adaptability to cultural differences. This element was then removed and its dimensions are present in other elements.

Based on the analysis of the six elements and their respective dimensions, at this stage, not all dimensions validated in the first phase remained as they were originally presented. The in-depth analysis required changes in the frame of reference of elements and dimensions that make up GIC. Whereas most of them did remain, some tended to be perceived in an integrated manner, others were confirmed, and some had to be reformulated, leading to a new relationship. The Table 3 shows the changes resulting from the post-phase II analysis.
This analysis led to a reflection on the proposed concept, as some elements were emphasized from a different angle. Two decisions were made: to complement the element of communication with the term intercultural, in order to clarify what kind of communication was being referred to, and the replacement of the term Negotiation with Articulation of cultural differences. Team members considered negotiation one of the stages of the process of articulation of cultural differences, and that in order for this articulation to be effective, one must have trust, openness and adaptability within the group.

Hence, the Concept was adjusted, culminating in: Group intercultural competence is the ability of the group to achieve its objectives effectively through social interaction, intercultural communication and efficient articulation of cultural differences, resulting from a process of group learning in a multicultural context (Lane et al., 2000; Gertsen, 1990; Dinges \& Baldwin, 1996; Byram, 1997; Bennet, 1986; Mendenhall \& Osland, 2002; Earley \& Ang (2003); Deardorff, 2004; Friedman \& Antal, 2005; Jokikokko, 2005; Moran et al., 2009; Bird et al., 2010; Lough, 2011; Fitch, 2012; Barmeyer \& Davoine, 2015).

Based on this analysis, we tried to assess the level of GIC of this group according to the team members' perceptions. Respondents were asked about their perception of the level of development of GIC (the concept was explained to them during data collection), on a scale of 1 to 5 , with 1 being very weak and 5 being very strong. The assessments varied between strong (3) and very strong (1): "... from what I can see, my perception is that it's a strong team, that has the strength to take matters into their own hands, to take on roles, to take responsibility, so I consider it strong." (E2). In addition to the self-assessments of the group members, we used the Intercultural Sensitivity Development Model developed by Hammer et al. (2003) to assess the team's level of GIC development. The instrument measures the level of competence through a development process based on the ability to perceive cultural differences and similarities and to modify one's behavior in a cultural context (Hammer, 2011). 
Table 3. Elements and Dimensions of the Development of Group Intercultural Competence.

\begin{tabular}{|c|c|c|}
\hline ELEMENT & INDIVIDUAL DIMENSION & GROUP DIMENSION \\
\hline \multirow{7}{*}{ Interaction } & Results orientation & \multirow{4}{*}{ Results management } \\
\hline & Understanding of group goals & \\
\hline & Strong, clear and detailed planning & \\
\hline & Understanding of the organization's strategic goals & \\
\hline & Clarity in describing roles & Clarity in describing roles \\
\hline & Team consolidation and engagement & $\begin{array}{l}\text { Team building (length of time working together and group } \\
\text { size) }\end{array}$ \\
\hline & Cohesion among team members & Cohesion among team members \\
\hline \multirow{6}{*}{ Efficacy } & Non-judgmental standpoint & \multirow{3}{*}{$\begin{array}{l}\text { Relationship building (non-judgemental standpoint, } \\
\text { appreciation of personal and cultural attributes) }\end{array}$} \\
\hline & $\begin{array}{l}\text { Relationship building } \\
\text { Appreciation of personal attributes }\end{array}$ & \\
\hline & $\begin{array}{l}\text { Appreciation of group members' values, beliefs } \\
\text { and behaviors }\end{array}$ & \\
\hline & Ability to manage complex situations & \\
\hline & Management of uncertainties & Conflict management \\
\hline & Successful interactions & \\
\hline \multirow{5}{*}{$\begin{array}{l}\text { Cultural } \\
\text { differences }\end{array}$} & Engagement of team members & Engagement of team members \\
\hline & Intellectual and cultural resource management & Global mindset (intellectual and cultural resources) \\
\hline & \multirow{3}{*}{ Global mindset } & $\begin{array}{l}\text { Ethnorelative vision (recognition of the existence and } \\
\text { importance of cultural differences) }\end{array}$ \\
\hline & & Flexibility \\
\hline & & Adaptability \\
\hline \multirow{4}{*}{$\frac{\text { Intercultural }}{\text { Communication }}$} & Clear and frank communication & Clear and frank communication \\
\hline & Precision in conveying and receiving messages & Precision in conveying and receiving messages \\
\hline & Constant feedback & Constant feedback \\
\hline & $\begin{array}{l}\text { Intercultural communication ability } \\
\text { Verbal and non-verbal skills }\end{array}$ & Intercultural communication ability \\
\hline \multirow{3}{*}{$\begin{array}{l}\text { Intercultural } \\
\text { Learning }\end{array}$} & Knowledge sharing orientation & Knowledge sharing orientation \\
\hline & \multirow{2}{*}{ Openness to intercultural learning } & Openness to intercultural learning (avoiding stereotypes) \\
\hline & & Trust \\
\hline
\end{tabular}

Note. Source: data from empirical research.

According to the model, the more mature stages of IC pointed out by the authors are adaptation and integration. It was detected that the group presented adaptability through openness, flexibility and articulation of cultural differences: "for us it is important to have certain diversity because it helps us come up with several points of view for the same situation ... There is [in a team that is competent in working with various cultures] diversity, responsiveness and, finally, adaptability." (E1). Regarding integration, the last level of intercultural maturity, we can say that the group, in aiming to adapt to cultural specificities of its members, generates a change in their frame of reference, integrating cultural specificities in an environment of transparency and harmonious interaction (Bennet, 1986; Bennet, 1993; Hammer, 2011). The high level of integration, pointed out by the group as a promoter of team cohesion, was also observed during the focus group. Whenever members were questioned about a certain topic, the entire group was encouraged to contribute with individual considerations.

After analyzing the elements and dimensions of GIC and assessing the degree of GIC development of the team, we then investigated how this multicultural team developed their degree of competence over time. To that end, we filtered the data available to understand how the elements and dimensions had contributed to this process. 
Transparency, ease of communication, ease of interaction, harmony, adaptability, respect and behavior similarity among group members were appointed as team characteristics that influenced the group's integration and high level of GIC. However, this level was not always that high. The process occurred in stages and was permeated by reflection, flexibility and change in styles, practices and routines, among other factors. Several changes took place in the team during the course of the three years they were analyzed. Among them, the five main ones that impacted several elements were: regionalization of the area; focus on Latin America; team heterogeneity; manager replacement; and the cancellation of an annual meeting.

Some practices were adopted by the team to tackle occasional difficulties in intercultural coexistence over time, including: (a) effective involvement of all team members in the selection processes; (b) development of a communication protocol; (c) use of cultural interpreters; (d) appropriateness of meeting schedules considering the differences in time zones; (e) non-judgemental standpoint; (f) flexible frame of reference, adapting processes and behaviors to the best solution for the team; (g) implementation of monthly meetings between project manager and local IT staff; (h) implementation of weekly meetings among members of the group; (i) creation of hangout spaces for informal conversations; (j) maintenance of constant feedback; (k) clarity of objectives, goals and roles within the group; and (l) managing occasional cultural conflicts naturally.

According to the respondents, the factors that acted as facilitators in the development process of GIC were: (a) cultural diversity broadened group perspectives and led to better solutions; (b) the existence of previous intercultural experience; (c) length of time working together; (d) high level of group trust and harmony; (e) personality similarities among members of the group; and (f) development of efficient telecommunication systems.

Finally, Human Resources and their services were highlighted at various times as factors that can either hinder or facilitate the development process of GIC: (a) recruitment and selection; (b) transfer policies; (c) career plan and development; (d) cross-cultural training.

Based on these analyses, it was possible to reflect on what the development process of GIC is: it is a process that occurs over time, since it is dynamic and variable, using the knowledge and experience of the group members in relation to interaction, efficacy, intercultural relationship (cultural differences) and intercultural communication, the result of a process of intercultural learning. As a process, it occurs in stages involving cognition, behavior and culture, interpersonal and intrapersonal, and expresses levels where a mature stage of development implies high integration among group members and welcoming of new members (Bennett, 1986; Berry et al., 1998; King \& Baxter-Magolda, 2005). The Figure 2 illustrates this theoretical proposal of GIC development, based on the literature and field research.

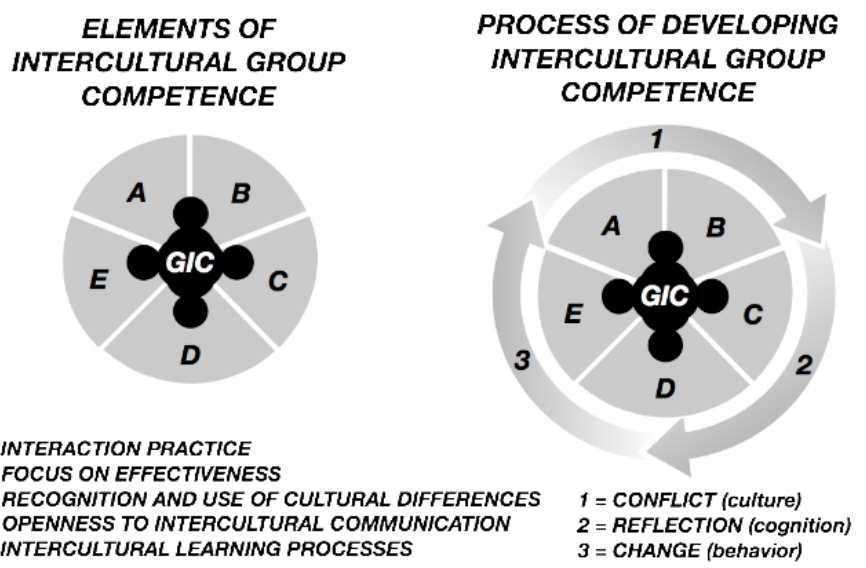

INTERCULTURAL LEARNING CYCLE

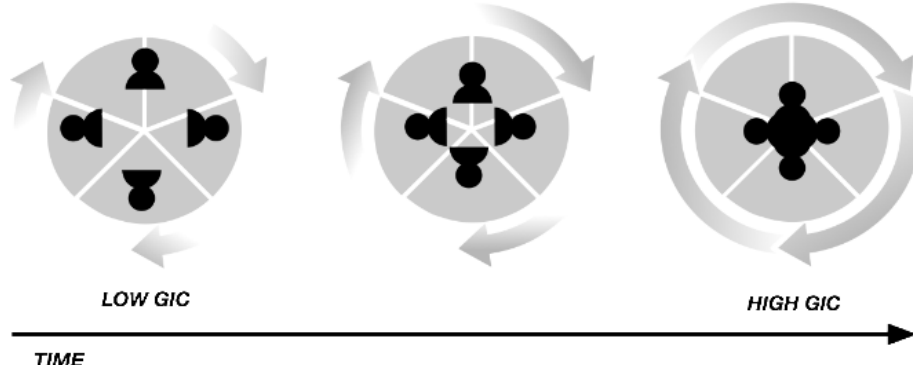

Figure 2. Process of Group Intercultural Competence Development.

Source: theoretical and empirical research data.

In the upper part of Figure 2, the components of the CIG are observed and how their development takes place through a continuous process of interaction between these elements permeated by conflicts (culture), reflection (cognition) and change (behavior) configured as stages of this process. In the lower part of the figure, the intercultural learning cycle is presented as the promoter of development of the CIG and evolves from low to high levels of interaction and integration among team members. 


\section{CONCLUSION}

As the main contribution of this article was to adjust and validate the concept of GIC and its development, and based on the results and the adjustments proposed upon field immersion, both concepts were altered to help the field to discuss intercultural competences on collective levels. Even the analysis of the data collected made it possible to identify the facilitating and inhibiting factors for the process of GIC development, based on the assessment of the practices carried out by the MNC that minimize the difficulties related to intercultural experience, and the advantages of working in multicultural environments. Some facilitators were more prominent in the development of GIC. These facilitators somehow boosted the development of GIC and its main contributions were cultural diversity broadening the group's perspectives, leading them to better results; the existence of previous intercultural experience, accelerating the group's learning processes; similarities in personality, contributing to the high level of trust and harmony in the group; and the development of efficient telecommunication systems, ensuring effective group interaction. Finally, a model was developed in order to explain the development process of GIC (Figure 2), and guide new research.

In conclusion, when the process of GIC development occurs towards more mature levels of competence, it is characterized by an upward spiral pyramidal process, where the lowest level evolves to higher levels through a cycle of intercultural learning. This evolution occurs over time and is permeated by conflict, reflection and change, covering the elements of GIC: interaction,

\section{REFERENCES}

Adair, W. L., Hideg, I., \& Spence, J. R. (2013). The culturally intelligent team: The impact of team cultural intelligence and cultural heterogeneity on team shared values. Journal of Cross-Cultural Psychology, 44(6), 941-962. https://doi.org/10.1177/0022022113492894

Adler, N. J., \& Gundersen, A. (2008). International dimensions of organizational behavior (5th ed.) Mason, $\mathrm{OH}$ : SouthWestern/Cengage Learning.

Barmeyer, C., \& Davoine, E. (2015, July). Intercultural competence of binational pairs as a supporting factor of negotiated culture in binational organisations: An analysis of the French-German case of Alleo. Paper presented in EGOS Colloquium, Athens, Greece, 31. efficacy, cultural differences, intercultural learning and intercultural communication, as both cause and consequence. Given its upward spiral pyramid characteristic, as the team develops towards higher levels of GIC, the learning cycle time is reduced, accelerating the response to cultural conflicts. The cycle is shorter, so learning occurs faster because incremental changes are more present. The process of GIC development, as well as the cycle of intercultural learning result in the creation of group practices that make it possible to minimize inhibiting factors in intercultural environments. The implementation of these practices also accelerates the process of GIC development, contributing to the progress of GIC levels.

In order to explore the GIC development process, as well as its elements and dimensions, some suggestions for future research are: to validate the GIC concept, using other MNCs, methods and research strategies; to examine the intercultural learning at the group and organizational level based on the proposed model, verifying if its relevance persists in other teams and contexts; to analyze how the process of intercultural learning supports the development of the IGC and, in correspondence, how the degree of GIC development is explained by the intercultural learning process; and to develop a quantitative model for the GIC concept, defining the antecedent, formative, mediating, moderating, and consequent elements and their impact on the performance of the MNC.

Bennett, M. J. (1986). A developmental approach to training for intercultural sensitivity. International Journal of Intercultural Relations, 10(2), 179-196. https://doi. org/10.1016/0147-1767(86)90005-2

Bennett, M. J. (1993). Towards ethnorelativism: A developmental model of intercultural sensitivity, In R. M. Paige (Ed.), Education for the intercultural experience (pp. 21-71). Yarmouth, ME: Intercultural Press.

Berry, J. W., Kim, U., Power, S., Young, M., \& Bujaki, M. (1998). Acculturation attitudes in plural societies. Applied Psychology, 38(2), 185-206. https://doi. org/10.1111/j.1464-0597.1989.tb01208.x

Bird, A., Mendenhall, M., Stevens, M. J., \& Oddou, G. (2010). Defining the content domain of intercultural competence forgloballeaders. Journalof ManagerialPsychology, 25(8), 810-828. https://doi.org/10.1108/02683941011089107 
Bücker, J., \& Poutsma, E. (2010). Global management competencies: A theoretical foundation. Journal of Managerial Psychology, 25(8), 829-844. https://doi. org/10.1108/02683941011089116

Bueno, J. M., \& Freitas, M. E. (2015). As equipes multiculturais em subsidiárias brasileiras de multinacionais: Um estudo de casos múltiplos. Organizações \& Sociedade, 22(72), 15-34. https://dx.doi.org/10.1590/1984-9230721

Byram, M. (1997). Teaching and assessing intercultural communicative competence. Clevedon, UK: Multilingual Matters.

Byram, M., Nichols, A., \& Stevens, D. (2001). Developing intercultural competence in practice. New York: Multilingual Matters.

Chen, M.-L., \& Lin, C.-P. (2013). Assessing the effects of cultural intelligence on team knowledge sharing from a sociocognitive perspective. Human Resource Management, 52(5), pp. 675-695. https://doi.org/10.1002/hrm.21558

Chevrier, S. (2000). Le management des équipes interculturelles. Paris: PUF.

Dalib, S., Harun, M., \& Yusoff, N. (2014). Reconceptualizing intercultural competence: A phenomenological investigation of students' intercultural experiences. Procedia: Social and Behavioral Sciences, 155(6), 130135. https://doi.org/10.1016/j.sbspro.2014.10.268

Deardorff, D. K. (2004). The identification and assessment of intercultural competence as a student outcome of internationalization at institutions of higher education in the United States (Doctoral dissertation). North Carolina State University, Raleigh, North Carolina, USA.

Deardorff, D. K. (2009). Implementing intercultural competence assessment. In D. K. Deardorff (Ed.), The SAGE handbook of intercultural competence ( $\mathrm{pp}$. 477-491). Thousand Oaks: Sage Publications.

Deardorff, D. K. (2015). Intercultural competence: Mapping the future research agenda. International Journal of Intercultural Relations, 48, 3-5. https://doi. org/10.1016/j.ijintrel.2015.03.002

Denzin, N. K., \& Lincoln, Y. S. (2007). O planejamento da pesquisa qualitativa teorias e abordagens (2nd ed., S. R. Netz, Trans.). Porto Alegre, RS: Artmed.

Dinges, N. G., \& Baldwin, K. D. (1996). Intercultural competence: A research perspective. In D. Landis, R. S. Bhagat (Eds.), Handbook of intercultural training (2nd. ed., pp. 106123) Thousand Oaks: SAGE Publications.

Dusi, P., Messetti, G., \& Steinbach, M. (2014). Skills, attitudes, relational abilities \& reflexivity: Competences for a multicultural society. Procedia: Social and Behavioral Sciences, 112(7), 538-547. https://doi.org/10.1016/j. sbspro.2014.01.1200

Earley P. C., \& Ang, S. (2003). Cultural intelligence: Individual interactions across cultures. Palo Alto: Stanford University Press.

Ferraro, G. P. (2001). The cultural dimension of international business. Upper Saddle River, NJ: Prentice Hall.
Fischer, T. M. D., Gondim, S. M. G., Pereira, M. E., Rodrigues, G. K. M., \& Pinheiro, L. L. (2009, setembro). Competências na gestão intercultural: desafios para aprendizagem e qualificação. Anais do Encontro Nacional da Associação Nacional de Pós-Graduação e Pesquisa em Administração, São Paulo, SP, Brazil, 33.

Fitch, K. (2012). Industry perceptions of intercultural competence in Singapore and Perth. Public Relations Review, 38(4), 609-618. https://doi.org/10.1016/j. pubrev.2012.06.002

Flick, U. (2009). Desenho da pesquisa qualitativa. Porto Alegre: Artmed.

Flores, J. G. (1994). Análisis de datos cualitativos: Aplicaciones a la investigación educativa. Spain: Promociones y Publicaciones Universitarias, PPU.

Friedman, V. J., \& Antal, A. B. (2005). Negotiating reality: A theory of action approach to intercultural competence. Management Learning, 36(1), pp. 69-86.

Gertsen, M. C. (1990). Intercultural competence and expatriates. The International Journal of Human Resource Management, 1(3), 341-362. https://doi. org/10.1080/09585199000000054

Gertsen, M. C., \& Soderberg, A. M. (2010). Expatriate stories about cultural encounters: A narrative approach to cultural learning processes in multinational companies. Scandinavian Journal of Management, 26(3), 248-257. https://doi.org/10.1016/j.scaman.2010.06.003

Gibbert, M., Ruigrok, W., \& Wicki, B. (2008). What passes as a rigorous case study?. Strategic Manangement Journal, 29(13), 1465-1474. https://doi.org/10.1002/smj.722

Groves, K. S., \& Feyerherm, A. E. (2011). Leader cultural intelligence in context: testing the moderating effects of team cultural diversity on leader and team performance. Group \& Organization Management, 36(5), pp. 535-66. https://doi.org/10.1177/1059601111415664

Gudykunst, W. B., \& Hammer, M. R. (1984). Dimensions of intercultural effectiveness: Culture specific or culture general? International Journal of Intercultural Relations, 8(1), 1-10. https://doi.org/10.1016/01471767(84)90003-8

Gudykunst, W. B., Hammer, M. R., \& Wiseman, R. L. (1977). An analysis of an integrated approach to crosscultural training. International Journal of Intercultural Relations, 1(2), 99-110. https://doi.org/10.1016/01471767(77)90045-1

Hammer, M. R. (2011). Additional cross-cultural validity testing of the Intercultural Development Inventory. International Journal of Intercultural Relations, 35(4), 474-487. https://doi.org/10.1016/j.ijintrel.2011.02.014

Hammer, M. R. (2015). The developmental paradigm for intercultural competence research. International Journal of Intercultural Relations, 48, 12-13. https://doi. org/10.1016/j.ijintrel.2015.03.004

Hammer, M. R., Bennett, M. J., \& Wiseman, R. L. (2003). Measuring intercultural sensitivity: The intercultural development inventory. International Journal of Intercultural Relations, 27(4), 421-443. https://doi. org/10.1016/S0147-1767(03)00032-4 
Hammer, M. R., Gudykunst, W. B., \& Wiseman, R. L. (1978). Dimensions of intercultural effectiveness: An exploratory study. International Journal of Intercultural Relations, 2(4), 382-393. https://doi. org/10.1016/0147-1767(78)90036-6

Jokikokko, K. (2005). Perspectives on intercultural competence. In R. Räsänen, J. San (Eds.), Conditions for intercultural learning and cooperation (pp. 89-106). Helsinki: Finnish Educational Research Association.

Kim, Y. Y. (1988). Communication and cross-cultural adaptation: An integrative theory. Philadelphia: Multilingual Matters.

King, P. M., \& Baxter-Magolda, M. B. (2005). A developmental model of intercultural maturity. Journal of College Student Development, 46(6), 571-592.

Koester, J., \& Olebe, M. (2003). The behavioral assessment scale for intercultural assessment. International Journal of Intercultural Relations, 12(3), 233-246. https://doi.org/10.1016/0147-1767(88)90017-X

Kupka, B. (2008). Creation of an instrument to assess intercultural communication competence for strategic international human resource management (Thesis, Doctor of Philosophy). University of Otago, Dunedin, New Zealand. Retrieved from http://hdl.handle. net/10523/163

Lane, H. W., DiStefano, J. J., \& Maznevski, M. L. (2000). International management behavior: Text, readings and cases (4th ed.), Malden, MA: Blackwell.

Lasonen, J. (2005). Reflexion sur l'interculturalité par rapport a l'education et au travail. Higher Education Policy, $18(4), 54-62$.

Lauring, J., \& Selmer, J. (2010). Multicultural organizations: Common language and group cohesiveness. International Journal of Cross Cultural Management, 10(3), pp. 267284. https://doi.org/10.1177/1470595810384587

Leung, K., Ang, S., \& Tan, M. L. (2014). Intercultural competence. The Annual Review of Organizational Psychology and Organizational Behavior, 1(1), 489-519. https://doi. org/10.1146/annurev-orgpsych-031413-091229

Lloyd, S., \& Härtel, C. (2010). Intercultural competencies for culturally diverse work teams. Journal of Managerial Psychology, 25(8), 845-875. https://doi. org/10.1108/02683941011089125

Lough, B. J. (2011). International volunteers' perceptions of intercultural competence. International Journal of Intercultural Relations, 35(4), 452-464. https://doi. org/10.1016/j.ijintrel.2010.06.002

Martin, J. N. (2015). Revisiting intercultural communication competence: Where to go from here. International Journal of Intercultural Relations, 48(1), 6-8. https:// doi.org/10.1016/j.ijintrel.2015.03.008

Matveev, A., \& Nelson, P. E. (2004). Cross cultural communication competence and multicultural team performance perceptions of American and Russian managers. International Journal of Cross Cultural Management, 4(2), pp. 253-270. https://doi. org/10.1177/1470595804044752
Mendenhall, M., \& Osland, J. S. (2002, June). An overview of the extant global leadership research. Symposium presentation, Academy of International Business, San Juan, Puerto Rico.

Merriam, S. B. (1998). Qualitative research and case study applications in education. Revised and expanded from "case study research in education". San Francisco: Jossey-Bass Publishers.

Moran, R. T., Youngdahl, W. E., \& Moran, S. V. (2009). Intercultural competence in business: Leading global projects. In D. K. Deardorff (Ed.), The SAGE handbook of intercultural competence (pp. 100-120). Thousand Oaks: SAGE Publications.

Moynihan, L. M., Peterson, R. S., \& Earley, P. C. (2006). Cultural intelligence and the multinational team experience: Does the experience of working in a multinational team improve cultural intelligence? In Y-R. Chen (Ed.), Research on Managing Groups and Teams (vol. 9, pp 299-323), Bingley, UK: Emerald Group.

Panggabean, H., Murniati, J., \& Tjitra, H. (2013). Profiling intercultural competence of Indonesians in Asian workgroups. International Journal of Intercultural Relations, 37(1), 86-98. https://doi.org/10.1016/j. ijintrel.2012.04.002

Rathje, S. (2007). Intercultural competence: The status and future of a controversial concept. Language and Intercultural Communication, 7(4), 254-266. https:// doi.org/10.2167/laic285.0

Schmidmeier, J., \& Takahashi, A. R. W. (2018). Competência intercultural grupal: Uma proposição de conceito. Cadernos EBAPE.BR, 16(1), 135-151. https://dx.doi. org/10.1590/1679-395159430

Soboleva, A. V., \& Obdalova, O. A. (2014). The methodology of intercultural competence development on the basis of a cognitive style-inclusive approach. Procedia - Social and Behavioral Sciences, 154, 155-161. https://doi. org/10.1016/j.sbspro.2014.10.128

Spitzberg, B. H., \& Changnon, G. (2009). Conceptualizing intercultural competence. In D. K. Deardorff (Ed.), The Sage handbook of intercultural competence (pp. 2-52). Thousand Oaks: SAGE Publications.

Wang. D., Taiwen, F., Freeman, S., Fan, D., \& Zhu, C. (2014). Unpacking the skill - cross-cultural competence mechanisms: Empirical evidence from Chinese expatriate managers. International Business Review, 23(3), 530-541. https://doi.org/10.1016/j. ibusrev.2013.09.001 


\section{Authors}

\section{Janete Schmidmeier}

Av. Prefeito Lothário Meissner, 632, $2^{\circ}$ andar, Jardim Botânico, 80210-170, Curitiba, PR, Brazil

E-mail address: janete.schmidmeier@gmail.com

๑ https://orcid.org/0000-0003-0825-1616

\section{Adriana Roseli Wunsch Takahashi}

Av. Prefeito Lothário Meissner, 632, $2^{\circ}$ andar, Jardim Botânico, 80210-170, Curitiba, PR, Brazil

E-mail address: adrianarwt@gmail.com

๑ https://orcid.org/0000-0002-4738-5273

\section{Janaina Maria Bueno*}

Av. João Naves de Ávila, 2121, Santa Mônica, 38408-100, Uberlândia, MG, Brazil

E-mail address: janaina.bueno@ufu.br

(1) https://orcid.org/0000-0002-0858-7657

* Corresponding author

\section{Contributions}

$\mathbf{1}^{\text {st }}$ author: conception and design of the research, data collection and analysis.

$2^{\text {nd }}$ author: orientation for the conception, research design and data analysis; revision of the final paper.

$3^{\text {rd }}$ author: co-orientation for data analysis; writing of the final version of the paper and its subsequent revisions.

\section{Funding}

The authors report that there is no financial support for the research in this article.

\section{Conflict of Interest}

The authors have stated that there is no conflict of interest.

\section{Plagiarism Check}

The RAC maintains the practice of submitting all documents approved for publication to the plagiarism check, using specific tools, e.g.: iThenticate. 